\title{
Numerical investigation of prediction method for spudcan settlement in normally consolidated kaolin clay
}

\author{
$Z Z \mathrm{Qiu}^{1, *}$, and $J T \mathrm{Yi}^{1}$ \\ ${ }^{1}$ School of Civil Engineering, Chongqing University, Chongqing 400045, China
}

\begin{abstract}
The post-installation consolidation settlement of spudcan foundations is an issue of concern for the offshore jack-up industry, especially when jack-up rigs operate for a long period such as those serving as production units. Although many centrifuge tests or numerical calculations have been conducted for spudcan behaviour after consolidation, there are no guidelines available to predict the consolidation settlement development. This paper reports a study dedicated to this subject. The spudcan installation and consolidation under operational load was continually simulated through the dual-stage Eulerian-Lagrangian analyses incorporating the modified Cam-clay model. Its feasibility and reliability were verified by comparison with other experimental results in literature. Parametric studies were carried out for spudcans under various soil parameters and geometrical conditions. A suitable method, Hyperbolic method, is proposed to predict spudcan settlement during consolidation with observed data
\end{abstract}

\section{Introduction}

The jack-up rig is a type of self-elevating mobile offshore platform, which has been extensively employed in oil and gas exploration activities in shallow to moderate water depths. A typical jack-up platform consists of a buoyant triangular hull for operation and several independent retractable legs, the latter of which rests on the seabed via saucer-shaped foundations known as "spudcans". In most clayey soils of relatively low permeability, the rapid spudcan preloading ensures fully undrained conditions [1]. Substantial amounts of excess pore pressures are often generated and accumulated. During the phase of operation, these accumulated pore pressure can lead to ongoing foundation settlement. Although offshore foundations are often designed with settlement tolerance, the large total settlements, in particular differential settlements amongst spudcans, can change the force balance and do harm to the structure, stability and onboard personnel. For instance, the field measurement data in the Gulf of Mexico [2] indicated additional spudcan settlements, another 1 to $2 \mathrm{~m}$, occurred at a near constant load in the wake of installation. Considering the industrial guideline such as SNAME (2008) [3] generally recommend a leg length reserve of $1.5 \mathrm{~m}$ above the upper guides, additional settlements of such amounts can pose threat to the safety of jack-ups. Hence, the effects of post-installation settlement should be carefully considered especially for the long-term application of jack-up unit [4].

So far, the spudcan behaviour during operation period has been investigated in a list of centrifuge tests conducted at the University of Western Australia [5-8]. And several finite element studies [9-11] which simulated the process of "penetration-unloadconsolidation-re-penetration" have also been conducted. However, only a limited amount of information was occasionally provided on the consolidation settlement, prior to the initiation of punch-through.

This paper reports a dedicated study on the consolidation settlement of spudcan foundation through finite element analyses. An effective stress large deformation finite element analysis, using the dual-stage EulerianLagrangian [12], was performed to verify and extend the parametric range beyond that of the centrifuge model tests. Based on numerical data, the applicability of conventional foundation models to predict consolidation settlement of spudcan foundation was assessed.

\section{Finite Element Simulation}

The "penetration-consolidation" process of spducan was investigated in this investigation using the novel dualstage Eulerian-Lagrangian scheme [9]. The simulation includes two consequential stages. The first stage, effective stress Eulerian calculation, modelled the continuous penetration of spudcan characterized by large deformation and strain. The second stage, coupled-flow Lagrangian calculation, analyse the post-installation consolidation settlement under a constant operational load, given the small soil strain and limited deformation and distortion. To ensure the two stages dovetail, rigorous mesh-to-mesh variable mapping was exercised at the end of the first stage and before the beginning of second stage, to map various state variables and pore pressures from effective stress Eulerian to coupled-flow Lagrangian calculation. Amongst these, the effective stress Eulerian finite element method was developed by 
$\mathrm{Yi}$ et al. [12] and herein implemented on the ABAQUS/Explicit platform through user material subroutine. The coupled-flow Lagrangian calculation was performed on the ABAQUS/Standard platform. The mesh-to-mesh mapping was realized in outside of ABAQUS environment through coding in Matlab. For full details of this dual-stage Eulerian-Lagrangian, reference to $[9,12]$ is required. The soil parameters used in the finite model refer to Table 1, while the permeability of the soil, $\mathrm{k}$, was expressed as function of the void ratio according to Mahmoodzadeh et al. [13].

Table 1. Properties of Malaysia kaolin clay.

\begin{tabular}{|c|c|}
\hline Property & $\begin{array}{c}\text { Malaysian } \\
\text { kaolin clay }\end{array}$ \\
\hline Liquid limit & $80 \%$ \\
\hline Plastic limit & $35 \%$ \\
\hline Specific gravity, $G_{s}$ & 2.60 \\
\hline Effecive unit weight, $\gamma^{\prime}$ & $6 \mathrm{KN} / \mathrm{m}$ \\
\hline $\begin{array}{c}\text { Effective Poisson's ratio, } \\
v^{r}\end{array}$ & 0.33 \\
\hline $\begin{array}{c}\text { Effective friction angle, } \\
\emptyset^{r}\end{array}$ & $23 \mathrm{deg}$ \\
\hline $\begin{array}{c}\text { Slope of critical state } \\
\text { line, } \mathrm{M}\end{array}$ & 0.9 \\
\hline $\begin{array}{c}\text { Slope of virgin } \\
\text { compression line(VCL), } \\
\lambda\end{array}$ & 0.244 \\
\hline $\begin{array}{c}\text { Slope of isotropic } \\
\text { swelling and } \\
\text { recompression line, } \mathrm{K}\end{array}$ & 2.354 \\
\hline $\begin{array}{c}\text { Void ratio at } \mathrm{p}^{\prime}=1 \mathrm{kPa} \text { on } \\
\text { VCL, } e_{N}\end{array}$ & 0.0523 \\
\hline
\end{tabular}

\section{Result and Discussion}

\subsection{Validation}

Comparisons with the experimentally measured penetration resistance and settlement time histories were performed to verify the robustness of the DSEL technique. Figure 1 shows measured and calculated penetration resistance during the spudcan installation with other results obtained from previous studies. According to Hossain et al. [14], the normalized penetration resistance (or bearing capacity factor) N_c after the occurrence of soil full backflow is given by

$$
N_{c}=\left(F-\gamma^{\prime} V\right) /\left(A S_{u e}\right)
$$

where $F$ is the spudcan penetration resistance, $\gamma$ ' soil's effective unit weight, $A$ the spudcan footprint area, $V$ the volume of the spudcan. $S_{u e}$ corresponds to $S_{u}$ at the penetration depth $d_{e}$, measured by T-bar penetrometer in the centrifuge experiment or deduced from MCC model.

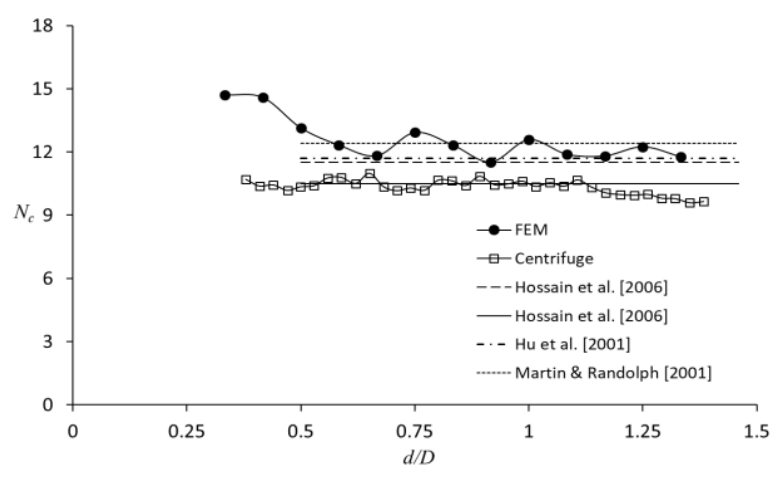

Fig. 1. Normalized penetration resistance $N_{c}$ at various depths

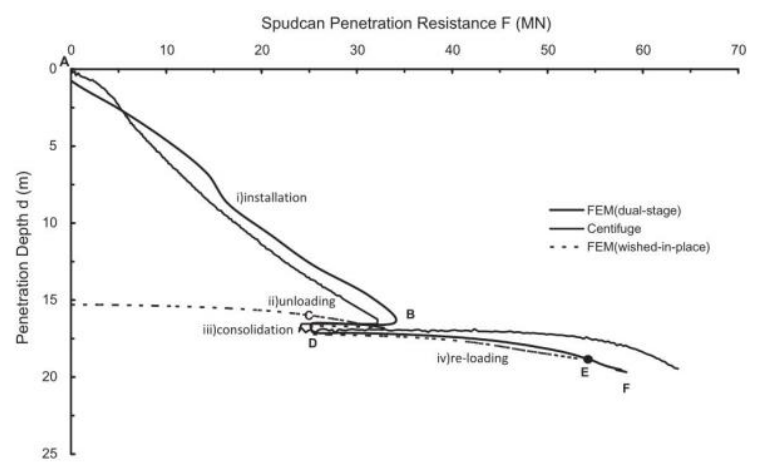

Fig. 2. Load-displacement response of spudcan

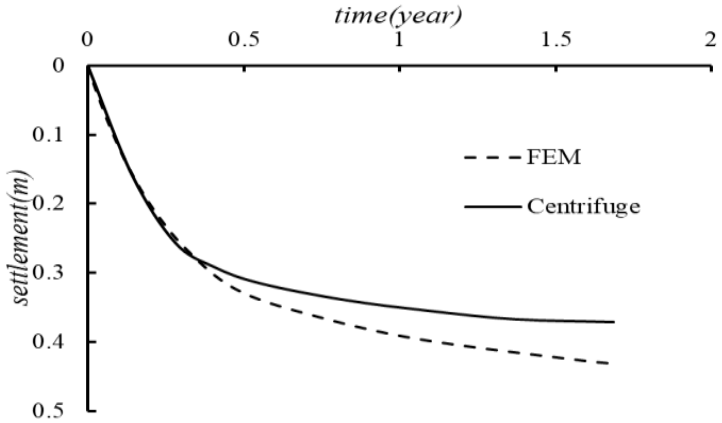

Fig. 3. Calculated spudcan consolidation settlement versus measurement

Figure 2 shows the calculated result compared with the load-settlement curve obtained from the centrifuge test. Details about the modelling equipment and other information have been reported by $\mathrm{Li}$ et al. [15]. The trends depicted by the experimental and numerical results are similar throughout the entire sequence of event. The penetration resistance during installation from centrifuge test is a bit lager than numerical result because the analysis does not take soil strength degradation into consolidation. However, the test resistance during re-loading seems smaller than that in finite element analysis, which may be caused by consolidation that happened when control mode changed. Figure 3 also shows the calculated settlement compared with the settlement measured from the centrifuge test. The result from FEM shows slightly Overestimation, which is probably caused by partial consolidation mentioned before. Overall the validity of the numerical model is verified. 


\subsection{Prediction Method}

In order to find a suitable prediction method, a series of parametric studies were conducted to explore the settlement time trend. Figure 4 shows settlement curves and their fitted lines under different soil parameters.

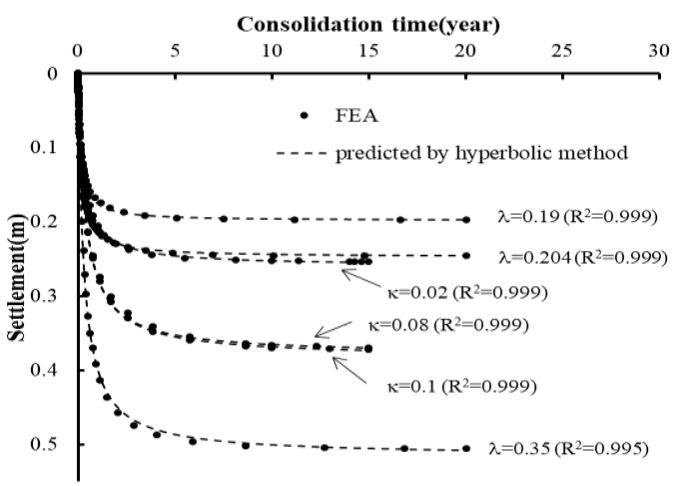

a

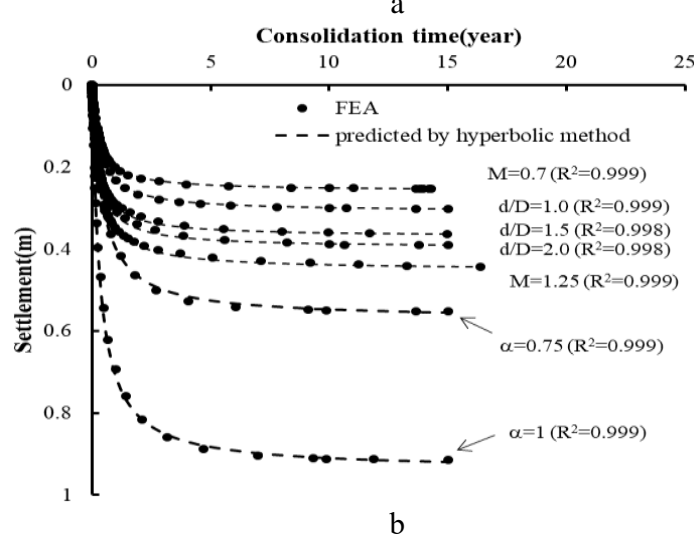

Fig. 4. a) Calculated settlement under different $\lambda, k$ b) Calculated settlement under different d, M

All settlement curves can be well approximated using a hyperbolic function of the following form:

$$
S_{t}=t /(\alpha+\beta t)
$$

where $\boldsymbol{\alpha}$ and $\boldsymbol{\beta}$ are the fitting coefficients. Therefore, the hyperbolic method [16] can be adopted to make prediction. Similar to hyperbolic method, Asaoka method, proposed by Asaoka (1978) [17], is widely used in settlement prediction. In this method, settlements at the same time interval are picked up firstly. Then this series of data fits the equation,

$$
S_{i}=\beta_{0}+\beta_{I} \cdot S_{i-1}
$$

where $S_{i}$ is the settlement at time $\mathrm{t}_{\mathrm{i}}, \beta_{0}$ and $\beta_{1}$ are parameters to be fitted. Figure 5 depicts the comparison between the above two prediction methods with observation data in different periods (from 0.5 to 2 years). Apparently, the predicted value of settlement after 6 years by hyperbolic method is much more accurate than by Asaoka method since the deviation of the former is $0.4-2.63 \%$ while the latter $9.67-28.51 \%$. Hyperbolic method is more suitable for settlement prediction. Table 2 also shows the prediction results under different conditions by 1.5 years of observations, including depth, load ratio and soil parameters (compared to conditions in centrifuge test). As can be seen, the correlation coefficient $\mathrm{R}^{2}$ is higher than 0.996 and the deviation of predicted value of final settlement is less than $5 \%$ in each case, implying good applicability of hyperbolic method. In summary, using Hyperbolic method with observed data within 1.5 years is proved to be accurate.
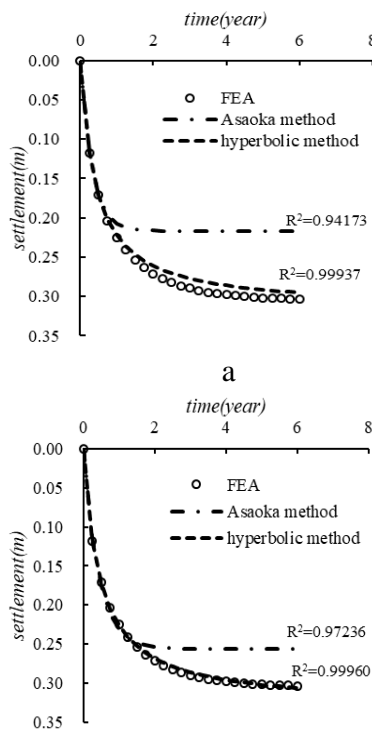

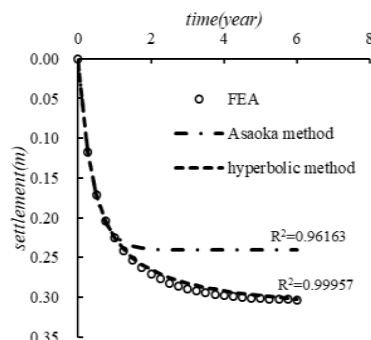

b

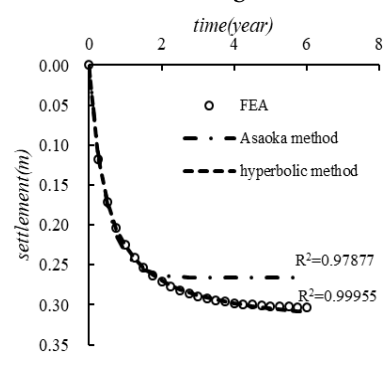

b
Fig. 5. a) prediction with 0.5 years of data b) prediction with 1 years of data c) prediction with 1.5 years of data d) prediction with 2 years of data

Table 2. Summary of prediction for different soil conditions

\begin{tabular}{|c|c|c|c|}
\hline \multirow{2}{*}{ Parameter } & Value & $\begin{array}{c}\text { the } \\
\text { correlation } \\
\text { coefficient } \mathbf{R}^{2}\end{array}$ & $\begin{array}{c}\text { Deviation of } \\
\text { final } \\
\text { settlement }\end{array}$ \\
\hline \multirow{2}{*}{$\kappa$} & 0.02 & 0.99946 & $2.17 \%$ \\
\cline { 2 - 4 } & 0.08 & 0.99935 & $-2.84 \%$ \\
\cline { 2 - 4 } & 0.1 & 0.99800 & $-4.87 \%$ \\
\hline \multirow{2}{*}{$\lambda$} & 0.19 & 0.99900 & $-2.52 \%$ \\
\cline { 2 - 4 } & 0.35 & 0.99977 & $1.63 \%$ \\
\hline \multirow{2}{*}{$\mathrm{D}$} & 1 & 0.99961 & $2.09 \%$ \\
\hline & $1 \mathrm{D}$ & 0.99958 & $2.01 \%$ \\
\cline { 2 - 4 } & $1.5 \mathrm{D}$ & 0.99801 & $-4.08 \%$ \\
\cline { 2 - 4 } & $2 \mathrm{D}$ & 0.99696 & $-4.99 \%$ \\
\hline
\end{tabular}

\section{Conclusion}

The DSEL analyses were carried out to continually model the installation and operation of spudcan. The calculation results were validated by comparison with experimental data reported in the literature. The main findings and conclusions of parametric studies can be summarized as follows: 1) the spudcan settlement time histories match hyperbolic curves very well, which can be fitted by Eq. 2; 2) Hyperbolic method is put forward for spudcan settlement prediction with observed data in 1.5 years and the superiority to Asaoka method is also 
proved. However, there were some limitations in the present study. a) The modified Cam-clay model used in this study is unable to model strain softening effect during penetration. A more advanced constitutive soil model can be adopted to further investigation. b) The prediction method reported in this study have to depend on observed data. A more general method without observation can be summarized in further study.

\section{References}

1. Gourvenec, Susan, and M. Randolph. Offshore Geotechnical Engineering (2011).

2. D. Menzies, and R. Roper, "Comparison of Jackup Rig Spudcan Penetration Methods in Clay," Offshore technology conference, Houston, Texas, U.S.A., Vol, OTC 19545 (2008).

3. SNAME, Guidelines for site specific assessment of mobile jack-up units, Technical \& Research Bulletin 5-5A, Society of Naval Architects and Marine Engineers, Jersey City, NJ, USA (2008).

4. BSI, "ISO 19905-1:2016: Petroleum and natural gas industries-site-specific assessment of mobile offshore units, Part 1: Jack-ups ", BSI standards publication, London, UK: BSI (2006).

5. E. R. Barbosa-Cruz, "Partial consolidation and breakthrough of shallow foundations in soft soil," $\mathrm{PhD}$, The University of Western Australia, Crawley, Australia (2007).

6. Bienen, Britta, and M. J. Cassidy. "Set Up and Resulting Punch-Through Risk of Jack-Up Spudcans during Installation." Journal of Geotechnical \& Geoenvironmental Engineering 139.12(2013):2048-2059.

7. S. A. Stanier, et al. "Observing the effects of sustained loading on spudcan footings in clay." Géotechnique 64.11(2015):918-926.

8. Bienen, Britta, and M. J. Cassidy and S. A. Stanier "Effects of Consolidation under a Penetrating
Footing in Carbonate Silty Clay," Journal of Geotechnical \& Geoenvironmental Engineering, 141(9), p. 04015040 (2015).

9. Yi, Jiang Tao, et al. "Post-installation pore-pressure changes around spudcan and long-term spudcan behaviour in soft clay." Computers \& Geotechnics 56.mar.(2014):133-147.

10. Wang, D, and B. Bienen. "Numerical investigation of penetration of a large-diameter footing into normally consolidated kaolin clay with a consolidation phase." Géotechnique 66.11(2016):1-6.

11. Ragni, Raffaele, et al. "Numerical modelling of the effects of consolidation on the undrained spudcan capacity under combined loading in silty clay." Computers \& Geotechnics 86.JUN.(2017):33-51.

12. Yi, Jiang Tao, et al. "Eulerian finite element analysis of excess pore pressure generated by spudcan installation into soft clay." Computers \& Geotechnics 42.may(2012):157-170.

13. Mahmoodzadeh, H. , M. F. Randolph, and D. Wang . "Numerical simulation of piezocone dissipation test in clays." Géotechnique 64.8(2014):657-666.

14. Hossain, M S, Hu, Y, and White, D J. "Cavity Stability and Bearing Capacity of Spudcan Foundations on Clay." 2006.

15. Li, Y.P., et at. "Effect of lattice leg on penetration resistance of spudcan foundations-Phsical and numerical modeling." (2014).

16. Tan, Thiam-Soon, T. Inoue, and Lee, Seng-Lip. "Hyperbolic method for consolidation analysis." Journal of Geotechnical Engineering 117.11(1991):1723-1737.

17. Asaoka. "Observational procedure of settlement prediction: Asaoka, A Soils Found, V18, N4, Dec 1978, P87-101." International Journal of Rock Mechanics \& Mining ences \& Geomechanics Abstracts 17.3(1980):53.. 